\begin{tabular}{|c|c|}
\hline Title & $\begin{array}{l}\text { Single photon emission in telecommunication band from an InA s quantum dot grown on InP with molecular-beam } \\
\text { epitaxy }\end{array}$ \\
\hline Author(s) & Liu, X.; A kahane, K.; Jahan, N. A.; Kobay ashi, N.; Sasaki, M.; Kumano, H.; Suemune, I. \\
\hline Citation & $\begin{array}{l}\text { A pplied phy sics letters, 103(6), } 061114 \\
\text { https://doi.org/10.1063/1.4817940 }\end{array}$ \\
\hline Issue Date & $2013-08-05$ \\
\hline Doc URL & http:/hdl.handle.net/2115/53289 \\
\hline Rights & $\begin{array}{l}\text { Copyright } 2013 \text { A merican Institute of Physics. This article may be downloaded for personal use only. A ny other use } \\
\text { requires prior permission of the author and the A merican Institute of Physics. The following article appeared in A ppl. } \\
\text { Phys. Lett. 103, } 061114 \text { (2013) and may be found at http://apl.aip.org/resource//applab } / 103 / 6 / p 061114 \text { s1 }\end{array}$ \\
\hline Type & article \\
\hline File Information & A pplPhysLett_103_061114.pdf \\
\hline
\end{tabular}

Instructions for use 


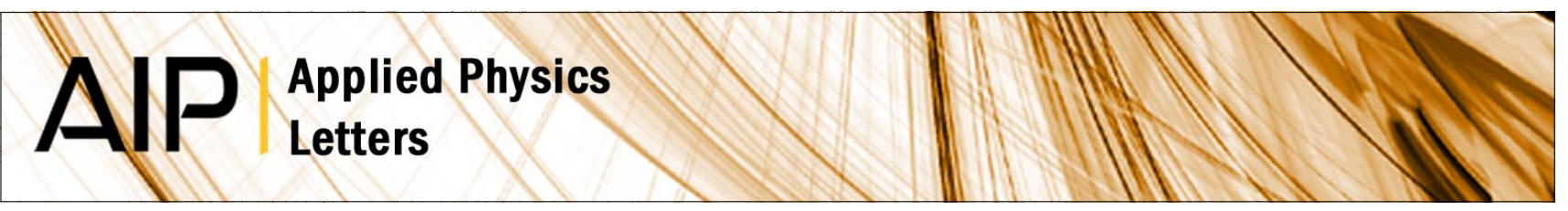

Single-photon emission in telecommunication band from an InAs quantum dot grown on InP with molecular-beam epitaxy

X. Liu, K. Akahane, N. A. Jahan, N. Kobayashi, M. Sasaki et al.

Citation: Appl. Phys. Lett. 103, 061114 (2013); doi: 10.1063/1.4817940

View online: http://dx.doi.org/10.1063/1.4817940

View Table of Contents: http://apl.aip.org/resource/1/APPLAB/v103/i6

Published by the AIP Publishing LLC.

Additional information on Appl. Phys. Lett.

Journal Homepage: http://apl.aip.org/

Journal Information: http://apl.aip.org/about/about_the_journal

Top downloads: http://apl.aip.org/features/most_downloaded

Information for Authors: http://apl.aip.org/authors

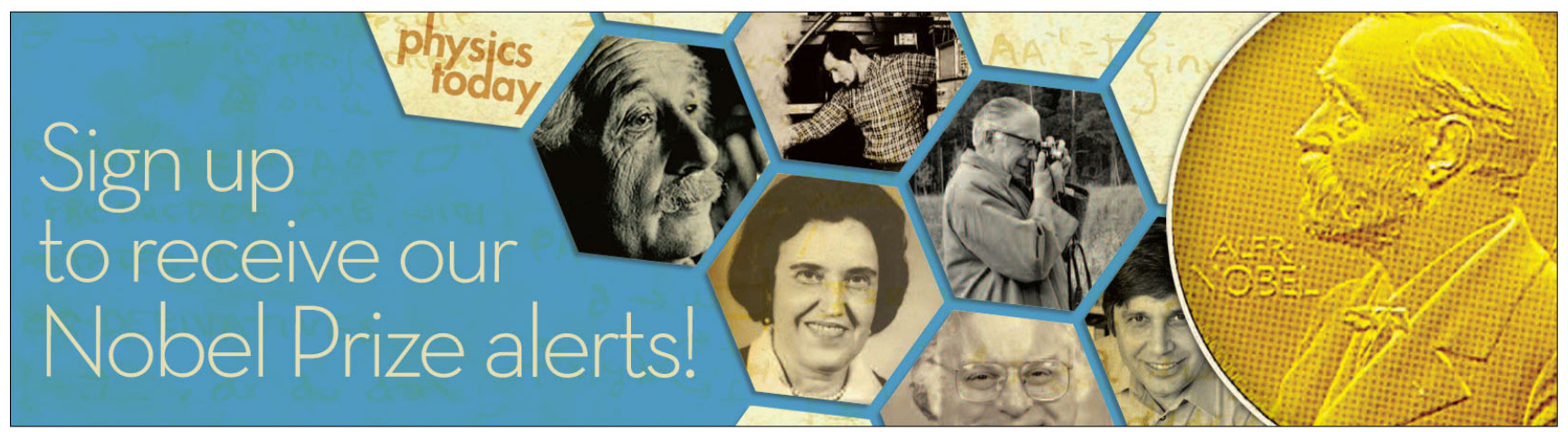




\title{
Single-photon emission in telecommunication band from an InAs quantum dot grown on InP with molecular-beam epitaxy
}

\author{
X. Liu, ${ }^{1, a)}$ K. Akahane,${ }^{2}$ N. A. Jahan, ${ }^{1}$ N. Kobayashi, ${ }^{1}$ M. Sasaki, ${ }^{2}$ H. Kumano, ${ }^{1}$ \\ and I. Suemune ${ }^{1}$ \\ ${ }^{1}$ Research Institute for Electronic Science, Hokkaido University, Sapporo 001-0021, Japan \\ ${ }^{2}$ National Institute of Information and Communications Technology, Koganei, Tokyo 184-8795, Japan
}

(Received 5 May 2013; accepted 24 July 2013; published online 8 August 2013)

\begin{abstract}
We report on the experimental demonstration of a single-photon source based on an InAs quantum dot (QD) on InP grown by molecular-beam epitaxy emitting in the telecommunication band. We develop a method to reduce the QD density to prevent inter-dot coupling via tunneling through coupled excited states. A single InAs QD embedded in an as-etched pillar structure exhibits intense and narrow emission lines. Photon antibunching is clearly observed using superconducting singlephoton detectors with high sensitivity, and further improvement of the generated single-photon purity is demonstrated with below-barrier-bandgap excitation. (C) 2013 AIP Publishing LLC.

[http://dx.doi.org/10.1063/1.4817940]
\end{abstract}

Single-photon emitters (SPEs) such as molecules, ${ }^{1}$ atoms, ${ }^{2}$ color centers in diamond, ${ }^{3}$ and semiconductor quantum dots $(\mathrm{QDs})^{4-10}$ have attracted much attention owing to their potential applications such as quantum communications, quantum cryptography, and optical quantum information processing. In particular, applications for a high bit rate and long-distance quantum key distribution (QKD) require the efficient generation of single photons in the telecommunication wavelength range $(1.3-1.55 \mu \mathrm{m})$ for an optical-fiber link. Among these systems, single QDs utilizing their discrete energy levels are very promising candidates, which offer high emission rates, narrow spectral line width, and wide tunability of emission wavelengths. There have been extensive studies on single-photon emissions from InAs QDs grown on GaAs substrates.${ }^{6,7}$ However from the viewpoint of extending the emission wavelengths to the telecommunication band, InAs QDs grown on InP substrates have the advantage due to the smaller lattice mismatch of $3.2 \%$ than that of $7.2 \%$ for InAs QDs on GaAs, where excess strain is crucial to satisfy both conditions of high optical quality and the extension of the emission wavelength.

Previously, the growth of InAs QDs on InP has been directed to QD laser applications for long-wavelength telecommunication, and high-density QDs have been studied for realizing high enough optical gain. For SPE applications, on the other hand, growth of low-density QDs is necessary but it was very much limited. There have been reports of singlephoton emission from InAs QDs grown on InP from two groups. ${ }^{5,8,9}$ Both groups employed metalorganic vapor-phase epitaxy (MOVPE) for the growth of InAs QDs. Historically, single-photon emission from QDs has been extensively studied with InAs QDs grown by molecular-beam epitaxy (MBE) on GaAs substrates. ${ }^{4}$ The main reasons employing MBE will be summarized into the following two points. One reason is the capability of controlling the QD size and uniformity by monitoring the growth process with reflection high-energy electron diffraction (RHEED). InAs QDs with

\footnotetext{
${ }^{a)}$ Electronic mail: liuxm@es.hokudai.ac.jp
}

macroscopic photoluminescence (PL) linewidth as narrow as $\sim 10 \mathrm{meV}$ have been prepared with MBE. ${ }^{10}$ This highly uniform growth capability of QDs is important to reproducibly control the QD emission into a target wavelength as singlephoton sources. Another reason is the high-purity growth capability of MBE. Charge state control of grown QDs is important to generate single photons at definite photon energies. Fluctuation of residual charges in a QD results in single-photon emissions of neutral or charged excitons and this reduces the single-photon generation rate at the desired photon energy. The absence of carrier gases as well as the ultra-high vacuum environment has the potential to prepare the highest achievable purity of the grown QDs and neighboring barrier layers. It is well known that the highest 2dimensional electron gas mobility of $\sim 1 \times 10^{7} \mathrm{~cm}^{2} \cdot \mathrm{V}^{-1} \cdot \mathrm{s}^{-1}$ has been achieved with the MBE grown layers. ${ }^{11}$ Full extension of these MBE potentialities to the telecommunicationband SPEs is the important step to realize practical optical-fiber-based quantum communications.

For this purpose of studying SPEs in the telecommunication band $(1.3-1.55 \mu \mathrm{m})$ with MBE-grown QDs, it is necessary to develop a method to grow low-density InAs QDs on InP substrates. However, MBE growth of InAs on InP (001) substrates generally results in high-density $\left(\sim 1 \times 10^{11} \mathrm{~cm}^{-2}\right)$ InAs quantum dashes elongated in the [1-10] direction. ${ }^{12-15}$ MBE growth on InP (311)B substrates results in circular InAs QDs, but this also leads to the high QD density on the order of $1 \times 10^{11} \mathrm{~cm}^{-2} \cdot{ }^{16,17}$ High QD density induces inter-dot coupling via tunneling through coupled excited states, ${ }^{18,19}$ and the resultant re-filling of the QD ground states with carriers from the neighboring QDs can prevent measuring photon antibunching from single QD for a limited time-resolution of an experimental setup. There have been reports of preparing lower-density InAs QDs on InP (001) substrates with a postgrowth annealing process ${ }^{20}$ and periodic alternated deposition of In and $\mathrm{As}^{21}$ using MBE, but single-photon emission has not been confirmed.

In this paper, we report the MBE growth of lowerdensity $\left(\sim 3 \times 10^{10} \mathrm{~cm}^{-2}\right)$ InAs QDs on $\operatorname{InP}(311)$ B substrates 
by simply increasing the QD growth temperature and the observation of sharp emission lines at $\sim 1.37 \mu \mathrm{m}$ from single QDs. We work on the Hanbury Brown and Twiss (HBT) measurements ${ }^{22}$ on the generated photons employing lownoise and high-sensitivity superconducting single-photon detectors (SSPDs) and demonstrate that the emission line in the telecommunication band exhibits a clear antibunching dip in the second-order correlation measurements, indicating single-photon emission. Further improvement under belowbarrier-bandgap excitation is also demonstrated.

The samples were grown by MBE (Veeco GEN II) on InP (311)B substrates. After thermal cleaning of the substrate, a 150-nm-thick lattice-matched $\mathrm{In}_{1-\mathrm{x}-\mathrm{y}} \mathrm{Ga}_{\mathrm{x}} \mathrm{Al}_{\mathrm{y}} \mathrm{As}$ buffer (barrier) layer was grown at $470^{\circ} \mathrm{C}$. Then, 5-monolayer (ML) InAs QDs in one sample are grown at $470^{\circ} \mathrm{C}$ as usual, which results in the high QD density. ${ }^{17}$ In the other sample, InAs QDs are grown at $530^{\circ} \mathrm{C}$. After the QD growth, the substrate temperature was decreased to $470^{\circ} \mathrm{C}$ to prevent the changes of QDs by annealing effect. Then a second barrier layer of 150-nm-thick $\mathrm{In}_{1-\mathrm{x}-\mathrm{y}} \mathrm{Ga}_{\mathrm{x}} \mathrm{Al}_{\mathrm{y}} \mathrm{As}$ was grown at the common temperature of $470^{\circ} \mathrm{C}$. Finally, 5-ML InAs QD layer was grown again at the same temperature as the first QD layer for the purpose of analyzing QD surface morphology. To mimic the growth temperature condition for the first QD layer before capping, the substrate temperature was set to $470{ }^{\circ} \mathrm{C}$ after the QD growth using same ramp rate and waiting time for $1 \mathrm{~min}$ before decreasing the substrate temperature to room temperature. Figures 1(a) and 1(b) show the AFM images of InAs QDs grown on $\mathrm{InP}(311) \mathrm{B}$ substrates at 470 and $530^{\circ} \mathrm{C}$, respectively. The scan size of the images is $500 \times 500 \mathrm{~nm}^{2}$. Obviously, the density of the QDs decreased with increasing the substrate temperature during the QD growth process. The averaged lateral size along the [-233] direction, averaged height, and QD density of the samples shown in Figs. 1(a) and 1(b) are given as follows: $40 \mathrm{~nm}, 3.1 \mathrm{~nm}$, and $9.06 \times 10^{10} / \mathrm{cm}^{2}$ for Fig. 1(a); $57 \mathrm{~nm}, 5.6 \mathrm{~nm}$, and $3.40 \times 10^{10} / \mathrm{cm}^{2}$ for Fig. 1(b), respectively. The QD lateral size and height increased with increasing the substrate temperature. This is related to the enhancement of surface diffusion of In adatoms that occurs in this temperature range, and the enhanced surface diffusion generally increases the lateral size and height of grown QDs. ${ }^{23}$

We have extensively studied the high-density sample shown in Fig. 1(a) grown at $470{ }^{\circ} \mathrm{C}$ and observed strong interdot coupling via tunneling through the coupled QD excited states. $^{18,19}$ This can prevent measuring photon antibunching
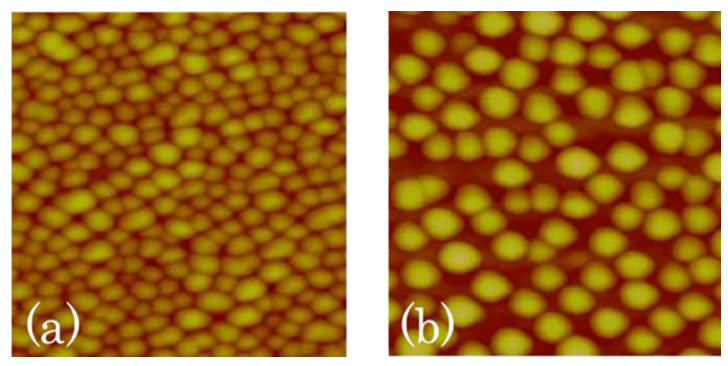

FIG. 1. AFM images of InAs QDs grown on InP (311)B substrates at QD growth temperature of (a) $470{ }^{\circ} \mathrm{C}$ and (b) $530^{\circ} \mathrm{C}$. The horizontal axis corresponds to the $[-233]$ direction. from single QDs due to the re-filling effect from neighboring QDs. Although the QD density reduction is by a factor of 3 between Figs. 1(a) and 1(b), the increased spacing of the neighboring QDs shown in Fig. 1(b) is effective to make it possible to measure photon antibunching from single QDs. In what follows, we focus on the optical properties of the lowdensity sample grown at $530^{\circ} \mathrm{C}$. PL spectrum measured on the as-grown, unprocessed sample surface with the diameter of several- $\mu \mathrm{m}$ area is shown in Fig. 2(a). A continuous-wave (CW) He-Ne laser at the wavelength of $633 \mathrm{~nm}$ was used for the excitation. It can be seen that the sample exhibits the QD emission peaked at around $1550 \mathrm{~nm}$. Except for the PL peaks from the InGaAlAs barriers and the InP substrate (broadened due to n-type doping), the emission of a wetting layer is absent in the case of InAs QDs grown on InP (311)B substrate. ${ }^{19}$ For the fabrication of well-controlled pillar structure with high yield and the isolation of a single QD, electronbeam lithography and sequential etching with inductively coupled plasma (ICP) reactive ion etching (RIE) were performed employing $\mathrm{Cl}_{2}$ as an etching gas. ${ }^{24}$ Figure 2(b) shows the secondary-electron microscope (SEM) image of one of the fabricated InP-based pillar structures with the typical height of $\sim 800 \mathrm{~nm}$.

The pillar sample placed inside a cryostat was also excited using the CW He-Ne laser. A near-infrared microscope objective lens with the numerical aperture of 0.42 was employed for the excitation of one selected pillar and for the collection of photons emitted from InAs QDs. The PL spectrum was measured by directing the emission into a 50 -cm-long double grating spectrometer equipped with a liquid-nitrogen-cooled InGaAs photodiode array detector. Figure 3(a) shows the PL spectrum observed from an InAs QD embedded in a pillar structure in the 1358-1376 nm wavelength range at $4 \mathrm{~K}$. The height and diameter of the measured pillar structure are $820 \mathrm{~nm}$ and $800 \mathrm{~nm}$, respectively. It can be seen that the PL spectrum shows the neutral exciton line $\left(\mathrm{X}^{0}\right)$, neutral biexciton line $\left(\mathrm{XX}^{0}\right)$, and negatively charged exciton line $\left(\mathrm{X}^{-}\right)$that peak at $1362.8 \mathrm{~nm}$, $1365.6 \mathrm{~nm}$, and $1370.8 \mathrm{~nm}$, respectively. The identification of these emission lines from the single QD was supported by the power and polarization dependent PL measurements. As expected, the $\mathrm{X}^{0}$ and $\mathrm{XX}^{0}$ lines exhibit the identical fine structure splitting (FSS) energy of $30 \mu \mathrm{eV}$ and the reciprocal
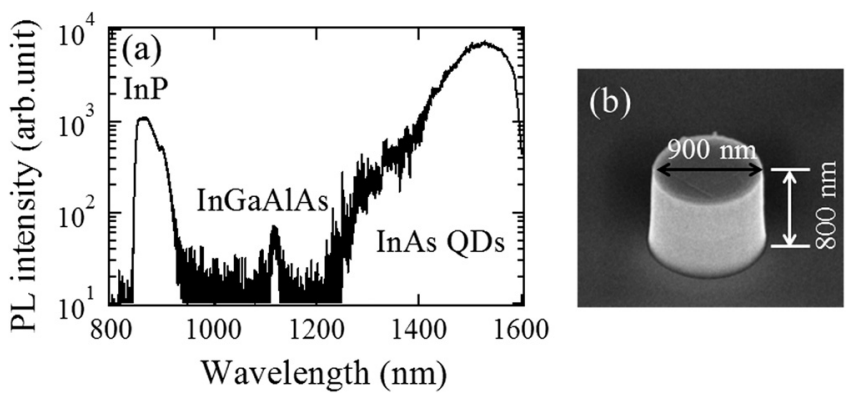

FIG. 2. (a) PL spectrum of 5-ML InAs QD sample at $4 \mathrm{~K}$. The QD emission is centered at around $1550 \mathrm{~nm}$. The peak around $1100 \mathrm{~nm}$ is the InGaAlAs barrier emission. The substrate emission around $900 \mathrm{~nm}$ is broadened due to n-type doping. (b) Side-view SEM image of an as-etched InP (311)B pillar structure. The pillar height is $\sim 800 \mathrm{~nm}$ and the top $300-\mathrm{nm}$ region consists of the 150-nm-thick InGaAlAs barrier/5ML InAs QD/150-nm-thick InGaAlAs barrier. 

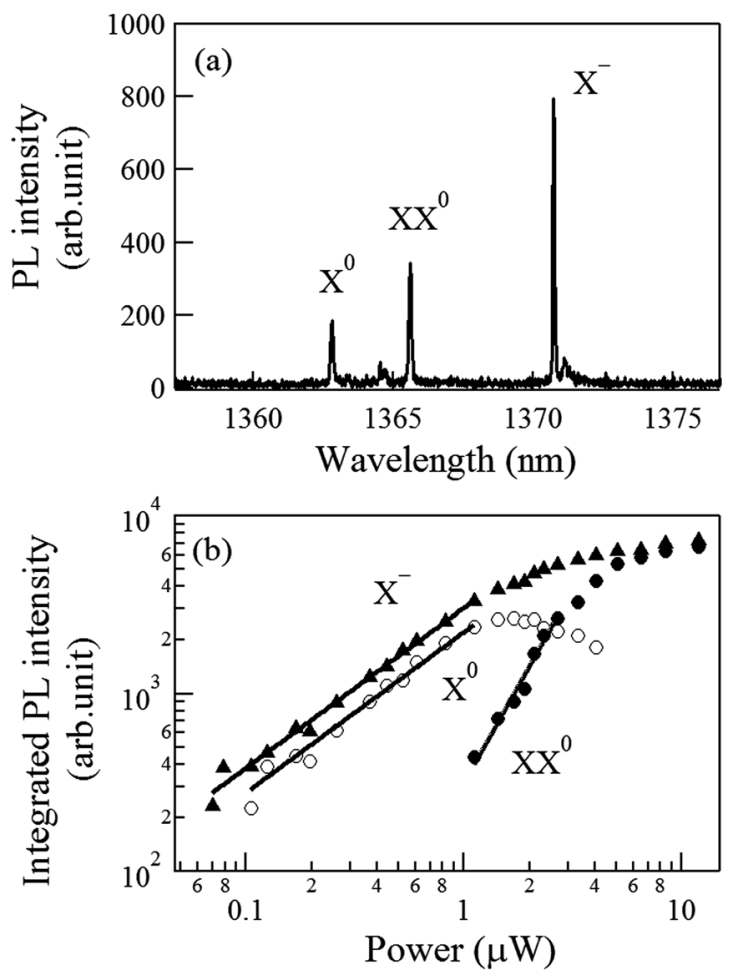

FIG. 3. (a) PL spectrum of an InAs QD in a pillar structure. The emission lines $\mathrm{X}^{0}, \mathrm{XX}^{0}$, and $\mathrm{X}^{-}$correspond to the neutral exciton, neutral biexciton, and negatively charged exciton emissions, respectively. (b) Integrated PL intensity as a function of the $\mathrm{CW}$ excitation power. The solid lines are guides to the eyes.

polarizations with each other. ${ }^{25}$ The integrated PL intensities of the $\mathrm{X}^{0}$ and $\mathrm{XX}^{0}$ lines show almost the respective linear and quadratic dependences on the excitation power as shown in Fig. 3(b). The assignment of the $\mathrm{X}^{-}$line has been corroborated by measuring the energy difference between this line and the $\mathrm{X}^{0}$ line. We find that the energy difference between the $\mathrm{X}^{-}$and $\mathrm{X}^{0}$ lines is $5.3 \mathrm{meV}$, which is consistent with the calculated shifts ${ }^{26}$ and experimental results. ${ }^{27}$ The FWHM of the $\mathrm{X}^{-}$line is narrower than that of other emission lines due to the absence of the FSS of the exciton state ${ }^{28}$ and is estimated to be $46 \mu \mathrm{eV}$, while the $\mathrm{X}^{0}$ and $\mathrm{XX}^{0}$ lines showed the apparent FWHM of 77 and $75 \mu \mathrm{eV}$ due to the FSS, respectively. The major PL peak around $1550 \mathrm{~nm}$ observed with the macroscopic-area measurements could not be well resolved into individual QD emission peaks even for small pillar diameters. Although the single QD emission around $1370 \mathrm{~nm}$ was insensitive to the pillar diameter, the PL spectrum around $1550 \mathrm{~nm}$ was reduced well below the single QD emission peak intensities for the smaller pillar diameter. This is explained by the carrier transport among larger QDs via inter-dot coupling ${ }^{18}$ toward the pillar surface and the related surface nonradiative recombination.

For the second-order photon correlation measurements, the exciton emission was coupled into a single-mode fiber with the microscope objective lens. To spectrally select a single QD emission, a tunable band-pass filter (BPF) with the FWHM of $0.5 \mathrm{~nm}$ was used. The spectrally selected photons were divided by a fiber beam splitter with the coupling ratio of 50:50 and then directed into the two SSPDs (Single Quantum BV). The detection events at the SSPDs were sent to a time-to-amplitude converter (TAC) as the start and stop signals. In order to compensate the electric delay of the detection system and obtain the information at the negative time delay, an optical delay of $\sim 125 \mathrm{~ns}$ was inserted into one of the optical paths after the beam splitter. Single-photon emission of the dominant emission $\mathrm{X}^{-}$is demonstrated by measuring the second-order correlation function $g^{(2)}(\tau)$ with the HBT setup, where $\tau$ is the delay time between the two optical path after the beam splitter.

Figure 4(a) shows the measured coincidence counts and the corresponding $g^{(2)}(\tau)$ without background subtraction under the excitation at the wavelength of $633 \mathrm{~nm}$. The excitation power was $0.95 \mu \mathrm{W}$, which was close to the saturation power of the QD. The measured data exhibit a clear antibunching dip at the zero time delay. The data could be fitted with the following expression:

$$
g^{(2)}(\tau)=1-\left[1-g^{(2)}(0)\right] \exp (-|\tau| / T),
$$

where $T$ is a time constant representing the combination of the emission lifetime and the inverse pumping rate, ${ }^{29}$ and $g^{(2)}(0)=0$ is an indication of perfect single-photon emission. To take into account the temporal resolution of the experimental setup, the measured second-order correlation function is fitted by the convolution of a real $g^{(2)}(\tau)$ and the instrument response function $h(\tau)^{29}$

$$
g_{\text {measured }}^{(2)}(\tau)=\int_{-\infty}^{\infty} h(\tau-t) g^{(2)}(t) d t
$$

where $h(\tau)$ is measured to be the Gaussian distribution function given by $A_{0} \exp \left(-\frac{\tau^{2}}{\Delta \tau^{2}}\right)$ with $\Delta \tau$ of 96 ps. The fitting in Fig. 4(a) shown by the solid line results in $T=0.95 \mathrm{~ns}$ and $g^{(2)}(0)=0.39 . g^{(2)}(0)$ below 0.5 shows the non-classical nature of the $\mathrm{X}^{-}$photon emission and indicates that the InAs QD in the pillar structure acts as a SPE. Contribution of uncorrelated

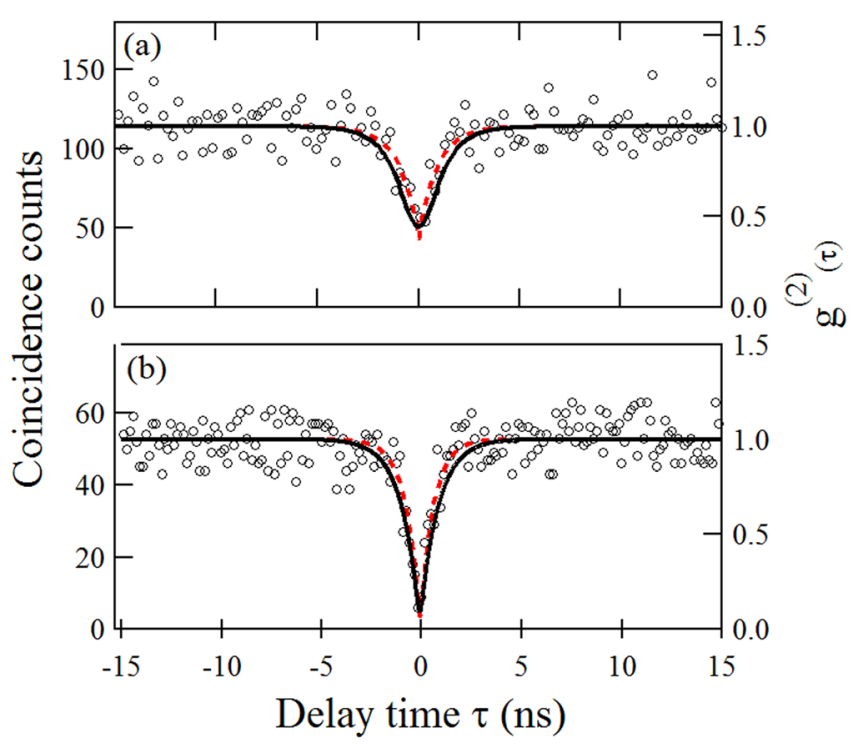

FIG. 4. Measured coincidence counts as well as the corresponding $\mathrm{g}^{(2)}(\tau)$ of the second-order correlation measurements under (a) the $633 \mathrm{~nm}$ excitation at $0.95 \mu \mathrm{W}$ and (b) the $1310 \mathrm{~nm}$ excitation at $20 \mu \mathrm{W}$. The solid curves are the fits of Eq. (1) convoluted with the instrument response function. The red-dashed curves represent the fits without the convolution. 
accidental coincidence counts to the estimated $g^{(2)}(0)$ is expressed as $B=\left(2 S D+D^{2}\right) /(S+D)^{2}$, in which $S$ and $D$ are the measured signal and dark count rates, respectively. ${ }^{30,31} \mathrm{In}$ this measurement, $S(D)$ was $\sim 3500$ (60) counts per second (cps) at the SSPDs. This leads to $B \sim 0.033$, and the $g^{(2)}(0)$ is recalculated to be 0.36 . The deviation from the ideal value of zero is related to the recapture processes and the associated multiphoton emission. In order to reduce $g^{(2)}(0)$, the excitation below the barrier bandgap at the wavelength of $1310 \mathrm{~nm}$ was performed and the result on the same emission line is shown in Fig. 4(b). The excitation power was increased to $20 \mu \mathrm{W}$ due to the lower absorption efficiency, but the clearer antibunching behavior with $g^{(2)}(0)=0.036$ was observed with $T=0.9 \mathrm{~ns}$. In this case, $B$ is calculated to be 0.027 with $S(D)$ of $\sim 1500(21)$ and the $g^{(2)}(0)$ as low as 0.009 can be deduced. The improvement in the antibunching can be explained by the reduction in the recapture contribution from the barriers and the associated multiphoton emission. These measurements directly show that we achieved single-photon emission with narrow line width and low $g^{(2)}(0)$ in the telecommunication wavelength band without performing quantum frequency down-conversion. ${ }^{32}$

In conclusion, we have demonstrated the single-photon emission at the wavelength of $\sim 1.37 \mu \mathrm{m}$ employing an asetched pillar structure incorporating an InAs/InP QD. The $g^{(2)}(0)$ as low as 0.009 is obtained. This became possible due to the reduction of the QD density by optimizing the MBE growth, which inhibited the re-filling of the QD ground state via tunneling through coupled excited states. ${ }^{18,19}$ In the present work, we collected photons from the as-etched pillar structure. Higher photon collection efficiency is expected by embedding the etched pillar into highly reflective metals such as silver. ${ }^{24}$ The study in this direction as well as the further MBE growth optimization is under way.

This work was partially supported by the Grand-in-Aid for Scientific Research (S), No. 24226007, Nanotechnology Platform by the Ministry of Education, Culture, Sports, Science and Technology, and SCOPE (Strategic Information and Communications R\&D Promotion Programme) from the Ministry of Internal Affairs and Communications, and nanomacro materials, devices, and systems alliance.

\footnotetext{
${ }^{1}$ M. Nothaft, S. Hohla, F. Jelezko, N. Fruhauf, J. Pflaum, and J. Wrachtrup, Nat. Commun. 3, 628 (2012).

${ }^{2}$ B. Darquié, M. P. A. Jones, J. Dingjan, J. Beugnon, S. Bergamini, Y. Sortais, G. Messin, A. Browaeys, and P. Grangier, Science 309, 454 (2005).

${ }^{3}$ A. Beveratos, R. Brouri, T. Gacoin, A. Villing, J.-Ph. Poizat, and P. Grangier, Phys. Rev. Lett. 89, 187901 (2002).

${ }^{4}$ P. Michler, A. Kiraz, C. Becher, W. V. Schoenfeld, P. M. Petroff, L. Zhang, E. Hu, and A. Imamoglu, Science 290, 2282 (2000).
}

${ }^{5}$ T. Miyazawa, K. Takemoto, Y. Sakuma, S. Hirose, T. Usuki, N. Yokoyama, M. Takatsu, and Y. Arakawa, Jpn. J. Appl. Phys., Part 2 44, L620 (2005).

${ }^{6}$ M. B. Ward, O. Z. Karimov, D. C. Unitt, Z. L. Yuan, P. See, D. G. Gevaux, A. J. Shields, P. Atkinson, and D. A. Ritchie, Appl. Phys. Lett. 86, 201111 (2005).

${ }^{7}$ P. M. Intallura, M. B. Ward, O. Z. Karimov, Z. L. Yuan, P. See, A. J. Shields, P. Atkinson, and D. A. Ritchie, Appl. Phys. Lett. 91, 161103 (2007).

${ }^{8}$ K. Takemoto, Y. Nambu, T. Miyazawa, K. Wakui, S. Hirose, T. Usuki, M. Takatsu, N. Yokoyama, K. Yoshino, A. Tomita, S. Yorozu, Y. Sakuma, and Y. Arakawa, Appl. Phys. Express 3, 092802 (2010).

${ }^{9}$ M. D. Birowosuto, H. Sumikura, S. Matsuo, H. Taniyama, P. J. van Veldhoven, R. Noetzel, and M. Notomi, Sci. Rep. 2, 321 (2012).

${ }^{10}$ Z. Mi and P. Bhattacharya, J. Appl. Phys. 98, 023510 (2005).

${ }^{11}$ M. R. Melloch, Thin Solid Films 231, 74 (1993).

${ }^{12}$ J. Brault, M. Gendry, O. Marty, M. Pitaval, J. Olivares, G. Grenet, and G. Hollinger, Appl. Surf. Sci. 162-163, 584 (2000).

${ }^{13}$ H. Yang, X. Mu, I. B. Zotova, Y. J. Ding, and G. J. Salamo, J. Appl. Phys. 91, 3925 (2002).

${ }^{14}$ M. Gendry, C. Monat, J. Brault, P. Regreny, G. Hollinger, B. Salem, G. Guillot, T. Benyattou, C. Bru-chevallier, G. Bremond, and O. Marty, J. Appl. Phys. 95, 4761 (2004).

${ }^{15}$ P. Podemski, R. Kudrawiec, J. Misiewicz, A. Somers, R. Schwertberger, J. P. Reithmaier, and A. Forchel, Appl. Phys. Lett. 89, 151902 (2006).

${ }^{16}$ S. Frechengues, V. Drouot, N. Bertru, B. Lambert, A. Loualiche, and A. Le Corre, J. Cryst. Growth 201/202, 1180 (1999).

${ }^{17}$ K. Akahane, N. Yamamoto, and M. Tsuchiya, Appl. Phys. Lett. 93, 041121 (2008).

${ }^{18}$ C. Hermannstädter, N. A. Jahan, J.-H. Huh, H. Sasakura, K. Akahane, M. Sasaki, and I. Suemune, New J. Phys. 14, 023037 (2012).

${ }^{19}$ N. A. Jahan, C. Hermannstädter, J.-H. Huh, H. Sasakura, T. J. Rotter, P. Ahirwar, G. Balakrishnan, K. Akahane, M. Sasaki, H. Kumano, and I. Suemune, J. Appl. Phys. 113, 033506 (2013).

${ }^{20}$ R. Kubota, T. Saiki, P. Regreny, A. Benamrouche, and M. Gendry, Jpn. J. Appl. Phys., Part 1 49, 041201 (2010).

${ }^{21}$ D. Fuster, A. Rivera, B. Alen, P. A.-Gonzalez, and Y. Gonzalez, Appl. Phys. Lett. 94, 133106 (2009).

${ }^{22}$ R. Hanbury Brown and R. Q. Twiss, Nature 177, 27 (1956).

${ }^{23}$ G. S. Solomon, J. A. Trezza, and J. S. Harris, Appl. Phys. Lett. 66, 991 (1995).

${ }^{24}$ J.-H. Huh, C. Hermannstädter, K. Akahane, N. A. Jahan, M. Sasaki, and I. Suemune, Jpn. J. Appl. Phys., Part 1 51, 06FF12 (2012).

${ }^{25}$ H. Kumano, S. Kimura, M. Endo, H. Sasakura, S. Adachi, S. Muto, and I. Suemune, J. Nanoelectron. Optoelectron. 1, 39 (2006).

${ }^{26}$ J. J. Finley, P. W. Fry, A. D. Ashmore, A. Lemaitre, A. I. Tartakovskii, R. Oulton, D. J. Mowbray, M. S. Skolnick, M. Hopkinson, P. D. Buckle, and P. A. Maksym, Phys. Rev. B 63, 161305 (2001).

${ }^{27}$ N. I. Cade, H. Gotoh, H. Kamada, T. Tawara, T. Sogawa, H. Nakano, and H. Okamoto, Appl. Phys. Lett. 87, 172101 (2005).

${ }^{28}$ R. Seguin, A. Schliwa, T. D. Germann, S. Rodt, K. Potschke, A. Strittmatter, U. W. Pohl, D. Bimberg, M. Winkelnkemper, T. Hammerschmidt, and P. Kratzer, Appl. Phys. Lett. 89, 263109 (2006).

${ }^{29}$ S. Kimura, H. Kumano, M. Endo, I. Suemune, T. Yokoi, H. Sasakura, S. Adachi, S. Muto, H. Z. Song, S. Hirose, and T. Usuki, Jpn. J. Appl. Phys., Part 2 44, L793 (2005).

${ }^{30}$ C. Becher, A. Kiraz, P. Michler, A. Imamoglu, W. V. Schoenfeld, P. M. Petroff, L. Zhang, and E. Hu, Phys. Rev. B 63, 121312(R) (2001).

${ }^{31}$ H. Nakajima, H. Kumano, H. Iijima, and I. Suemune, Appl. Phys. Lett. 101, 161107 (2012).

${ }^{32}$ S. Zaske, A. Lenhard, C. A. Keßler, J. Kettler, C. Hepp, C. Arend, R. Albrecht, W.-M. Schulz, M. Jetter, P. Michler, and C. Becher, Phys. Rev. Lett. 109, 147404 (2012). 